\title{
O INVESTIMENTO SOCIAL PRIVADO E O MODELO DE ACORDO DE COOPERAÇÃO DO MROSC
}

\section{Thiago Lopes Ferraz Donnini}

\begin{abstract}
// resumo
O artigo discute possíveis impactos negativos decorrentes da imprecisão do texto legal e da regulamentação do Marco Regulatório das Organizações da Sociedade Civil (MROSC) para iniciativas de investimento social privado (ISP). Partindo dos dados do Censo GIFE 2018 sobre estratégias de "aproximações com políticas públicas", particularmente a respeito das principais dificuldades encontradas pelos investidores em suas relações com entes governamentais, o estudo analisa uma das possíveis causas de retração ou inibição desse tipo de iniciativa. Sustenta-se que o modelo de acordo de cooperação, previsto pelo MROSC, pode levar à configuração de relações desproporcionalmente rígidas e juridicamente mais inseguras. Uma das principais evidências dessa constatação é o conjunto de decretos de regulamentação da lei.
\end{abstract}

palavras-chave: investimento social privado | parcerias com a administração pública | marco regulatório das organizações da sociedade civil. 


\section{OS ARTIGOS GIFE}

A série Artigos GIFE publica reflexões e análises de pesquisadores brasileiros de diferentes áreas do saber com o objetivo de estimular, ampliar e disseminar a produção de conhecimento qualificado sobre o campo da filantropia, do investimento social privado e da sociedade civil no Brasil.

A partir da premissa de que a produção de conhecimento sobre esses temas tem um papel fundamental na expansão, diversificação e qualificação da ação pública pela sociedade, a iniciativa também pretende contribuir para ampliar as conexões entre o setor, as universidades e os centros de pesquisa, promovendo e apoiando o envolvimento de novos atores com a temática e a circulação ampliada de ideias em torno dela.

Este texto integra a quarta edição dos Artigos GIFE, que propõe a publicação mensal de artigos selecionados por meio de chamada pública e convite a autores especialistas em temáticas específicas e relevantes para o setor, buscando apoiar e fomentar a produção de conhecimento sobre o investimento social no Brasil.

O Grupo de Institutos Fundações e Empresas (GIFE) é uma organização sem fins lucrativos que reúne associados de origem empresarial, familiar ou independente que investem em projetos de interesse público. Criado em 1989 como grupo de troca e colaboração e institucionalizado em 1995 por 25 organizações, tornou-se referência no campo da filantropia e do investimento social privado no Brasil.

Nesses mais de 20 anos de atuação, tem contribuído para o fortalecimento de práticas e ações a serviço do bem comum no país, trabalhando para expandir, qualificar e fortalecer o investimento social privado, diversificar e ampliar atores e recursos, criando referências e estimulando boas práticas de gestão, bem como articulando o setor com a sociedade e a agenda pública. Atualmente, o GIFE reúne mais de 150 associados que, somados, aportam mais de $\mathrm{R} \$ 3$ bilhões por ano em projetos próprios e no apoio a projetos de terceiros. 


\section{INTRODUÇÃO}

O Censo GIFE 2018 indica que o percentual de investidores sociais privados que desenvolvem iniciativas de "aproximação com políticas públicas" - o que abarca as mais diferentes estratégias de interação com entes públicos - oscilou de $86 \%$ para $80 \%$. A edição anterior do Censo GIFE, de 2016, continha dados do período em que o Marco Regulatório das Organizações da Sociedade Civil (MROSC, lei 13.019/14) ainda não vigorava. A nova edição da pesquisa narra que, entre as principais dificuldades enfrentadas pelos investidores, estão: a morosidade do poder público (32\%), a descontinuidade de iniciativas devido a mudanças políticas $(30 \%)$ e o excesso de burocracia na execução de projetos ou programas (21\%). De outro lado, entre aqueles que não desenvolvem estratégias de "aproximação com políticas públicas", os principais motivos apontados são: os eventuais impactos negativos para a imagem das organizações pela associação com entes públicos (38\%), as dificuldades para concretizar parcerias e executar projetos ou programas devido à forma de funcionamento do setor público (23\%) e, ainda, o risco de descontinuidade de iniciativas em decorrência de mudanças políticas (23\%) (GIFE, 2019).

Há, ainda, no Censo GIFE, um indicador correlato, que envolve a influência do ambiente de atuação das organizações da sociedade civil (OSC) para planejamento de ações de investidores. Segundo a pesquisa, o MROSC aparece como um dos temas destacados de mobilização do campo. A pesquisa indica que $30 \%$ dos respondentes afirmaram ter se engajado na pauta do MROSC nos últimos dois anos e $33 \%$ estavam vinculados a esse debate ainda antes disso (GIFE, 2019).

No entanto, é provável que a mobilização de parcela dos investidores a favor do MROSC estivesse, à época, relacionada a uma visão ampla sobre o ambiente de atuação das OSC no país. O MROSC, possivelmente, era entendido como uma agenda de reformas legislativas mais abrangente e não apenas como uma lei de parcerias entre OSC e entes públicos - o que efetivamente representou, ao final. Também se pode assumir que eventuais impactos negativos do MROSC para o investimento social privado (ISP) dificilmente poderiam ser estimados durante as articulações que o precederam. Isso porque a lei 13.019/14 define, essencialmente, uma disciplina para o fomento público de projetos e atividades de OSC (BRASIL, 2014). Seria difícil imaginar que a mesma lei produziria um cenário de burocratização e insegurança jurídica para ações executadas sem a mobilização de recursos públicos, mediante parcerias. Mas é o que pode estar ocorrendo.

Para demonstrar como esse risco pode estar se configurando, o artigo apresenta, inicialmente, quais são os modelos contratuais que poderiam, em tese, formalizar iniciativas de ISP em "aproximação com políticas públicas”. Em seguida, define, a partir das normas vigentes, uma concepção ideal para a modalidade contratual de acordo de cooperação, prevista pelo MROSC, e eventualmente aplicada às iniciativas de ISP. E, finalmente, identifica os obstáculos que podem dificultar a celebração e a execução de parcerias voltadas ao ISP. 


\section{MODELOS CONTRATUAIS PARA INICIATIVAS DE ISP EM "APROXIMAÇÃO COM POLITTICAS PÚBLICAS ${ }^{\prime \prime}$}

Ainda por meio dos indicadores do Censo GIFE - manejados a partir do portal Mosaico -, é possível relacionar algumas das iniciativas de "aproximação com políticas públicas" com modelos contratuais potencialmente aptos à formalização de uma relação jurídica com entes públicos (Tabela 1). No entanto, nem todas as iniciativas são, invariavelmente, sujeitas à formalização. Parte das estratégias relacionadas na pesquisa - e aqui desconsideradas - independeria de celebração de ajuste contratual. É o caso, por exemplo, do controle social de políticas públicas e das ações de advocacy, entre outras iniciativas exercitáveis de forma autônoma por qualquer cidadão, cidadã ou OSC.

Em outros casos, é possível apontar até mais de um modelo contratual aplicável, já que não se tem acesso aos atributos detalhados de cada iniciativa, particularmente tempo de execução e grau de envolvimento da administração pública na consecução dos objetos pactuados. Seja como for, o que se busca, com a classificação, é apenas indicar a relevância de um dos modelos potencialmente aplicáveis para essas relações.

Os modelos contratuais utilizáveis seriam, de acordo com a Tabela 1, os acordos de cooperação, disciplinado pelo MROSC ou pelo art. 116 da lei 8.666/93 - de licitações e contratos administrativos -, e os contratos de doação, regido pelo art. 54 dessa lei e pelo Código Civil Brasileiro ${ }^{1}$ (BRASIL, 1993, 2002).

Tabela 1 - Modelos contratuais adequados a estratégias de "aproximação com políticas públicas"

\section{Estratégias de aproximação com políticas públicas (GIFE, 2019)} Desenvolve metodologias/tecnologias sociais com o
objetivo de serem incorporadas às políticas públicas

Contribui com a produção de conhecimento para auxiliar a elaboração de políticas ou a gestão pública (ex.: análise de dados governamentais, produção de diagnósticos socioterritoriais)

Dá apoio técnico especializado para elaboração, execução e monitoramento de projetos/programas governamentais

Faz gestão e execução de projetos sociais de iniciativa do poder público
Organizações que declaram utilizar (GIFE, 2019)

57

51

36

11

41

58

25

11

12

7
Vínculos jurídicos potencialmente adequados para a relação com entes públicos

Acordo de cooperação ou contrato de doação de bens/ serviços

Acordo de cooperação ou contrato de doação de bens/ serviços

Acordo de cooperação ou contrato de doação de bens/ serviços

Acordo de cooperação (assumindo que não se trata de iniciativa financiada pela administração pública, mas sim de ISP)

Articula e mobiliza atores para elaboração, execução e monitoramento de políticas públicas

Acordo de cooperação

Desenvolve ações de formação/ capacitação de gestores ou servidores públicos ção de bens/ serviços

Prioriza desenvolvimento de iniciativas inovadoras com foco na solução de desafios das políticas públicas (ex.: escala, redução de custo etc.)

Disponibiliza plataformas digitais e/ ou aplicativos de gestão da informação a órgãos ou equipamentos sociais da administração pública

Oferece equipamentos e infraestrutura para execução de políticas públicas (ex.: disponibiliza transporte, local para encontros etc.)

Dá apoio financeiro direto a equipamentos públicos
Acordo de cooperação

Acordo de cooperação ou contrato de doação de bens/ serviços

Contrato de doação de bens/ serviços

Contrato de doação de bens/ serviços

Fonte: GIFE (2019); elaboração própria.

1 Cabe lembrar, ainda, do modelo de fundos patrimoniais, tal como definido pela lei 13.800/19 (BRASIL, 2019). Embora essencialmente destinado à captação de recursos privados para ações de interesse público - especialmente de instituições estatais -, trata-se de arranjo extremamente complexo, cuja concretização tende a ser muito mais rara e, assim, não pode ser considerada, ao menos por ora, como uma referência. 
Como ressaltado, a descrição das estratégias de "aproximação com políticas públicas" pelo Censo GIFE (2019) permite apenas inferências sobre os modelos jurídicos que poderiam ser adotados em cada caso. Ainda assim, são dados suficientes para uma avaliação sobre eventuais impactos do modelo de acordo de cooperação previsto no MROSC para o ISP. Isso porque, em primeiro lugar o que se observa, nessas relações, é a formalização escrita e pública, não sendo admitidos contratos verbais. Em segundo lugar, a utilização do MROSC tende a se tornar muito comum em razão da abrangência da lei, que atrai para seu regime jurídico, como regra, as parcerias entre administração pública e OSC (art. 41)².

\section{ISP E RELAÇÕES JURIDICAS COM ENTES PÜBLICOS}

Alguns contratos, no direito administrativo - ramo do direito que disciplina o funcionamento da administração pública -, têm uma disciplina marcada pela sujeição do particular a condições bastante rígidas. É o caso dos contratos administrativos comuns (obras, compras e serviços), das várias formas de concessão (parcerias de investimento) e dos contratos de fomento ao terceiro setor (parcerias sociais). Para essas modalidades, são estabelecidos, pormenorizadamente, critérios de seleção impessoal e diversos rigores para as etapas de execução e encerramento dos ajustes. Todas, de certa maneira, fixam prerrogativas exclusivas da administração pública frente ao particular. Há, por outro lado, um campo de relações contratuais em que se admite certo grau de horizontalidade ou nivelamento entre a administração pública e o particular (DI PIETRO, 2010, p. 258). Nelas, ao menos em tese, a disciplina do direito administrativo seria mais superficial e menos associada ao exercício de poderes administrativos, já que não preveem aplicação de recursos públicos, seja remunerando particulares, financiando suas ações ou lhes destinando bens públicos.

O ISP pode se materializar, na maioria das estratégias de "aproximação com políticas públicas" descritas pelo Censo GIFE (2019), como uma destinação de recursos privados para diferentes finalidades de interesse público (GIFE, s.d.). Assim, o seu acolhimento, pela administração pública, tenderia a ocorrer no campo de relações jurídicas marcadas por maior horizontalidade. Isso porque, a princípio, a posição exercida pela administração pública não seria a de uma autoridade voltada a garantir um serviço essencial ${ }^{3}$. Ou seja: não haveria justificativa legal para submeter o particular aos mesmos rigores estabelecidos naquele primeiro campo de contratações.

Seriam, assim, diversos os contratos que poderiam instrumentalizar as iniciativas de ISP. Algumas ações podem ser amoldadas, por exemplo, sob o regime dos contratos civis da administração pública (CARVALHAES NETO, 2011). Desse modo, quando se trata de oferecer, gratuitamente, a utilização de um bem privado em favor da administração pública, por certo período (por exemplo, empréstimo de um imóvel para instalação de um serviço público), utiliza-se o contrato de comodato. Ou, ainda, quando se trata de prover condições materiais para a melhor execução de uma política pública (por exemplo, oferta de novos equipamentos de informática de uma escola, reformas ou adaptações prediais, atualização de acervos bibliotecários etc.), utiliza-se o contrato de doação de bens e/ ou serviços (HIRATA, 2019). Como apontado, a doação pode ser um dos modelos potencialmente aptos à formalização de ISP em “aproximações com políticas públicas”. O decreto federal 9.764, de 11 de abril de 2019, por exemplo, "dispõe sobre o recebimento de doações de bens móveis e de serviços de pessoas físicas ou jurídicas de direito privado pelos órgãos e pelas entidades da administração pública federal direta, autárquica e fundacional” (BRASIL, 2019).

Além disso, há iniciativas de ISP cuja finalidade de interesse público somente pode ser alcançada por meio da mútua colaboração entre as partes. Isso ocorre quando as ações exigem mobilização conjunta e continuada de esforços de cada uma das partes para a obtenção de resultados. Em geral, envolvem a constituição de grupos de trabalho, que se articulam, por exemplo, para levantar dados, desenvolver

\footnotetext{
2 "Art. 41. Ressalvado o disposto no art. $3^{\circ}$ e no parágrafo único do art. 84, serão celebradas nos termos desta Lei as parcerias entre a administração pública e as entidades referidas no inciso I do art. $2^{\circ}$.” (BRASIL, 2014).

3 Ressalvando, no entanto, estratégias que parecem mais raras, como a "gestão direta de equipamentos públicos", indicada no Censo GIFE (2019), sobre as quais não há mais detalhes, mas que poderiam ensejar situação diversa.
} 
capacitações, monitorar políticas públicas, entre outras ações que, concatenadas, conformam extensos programas de interesse público e até de reposicionamento institucional para órgãos e entidades públicas. Para atingir esses objetivos, há arranjos contratuais também marcados por maior grau de horizontalidade entre a administração pública e o particular. São as formas de cooperação que não envolvem transferência de recursos públicos financeiros em favor do parceiro privado.

A celebração de acordos de cooperação pode se dar sob a regência do art. 116 da lei de licitações e contratos administrativos (que disciplina convênios e instrumentos congêneres, dentre os quais se reconhece, implicitamente, o acordo de cooperação técnica e o protocolo de intenções) ou do MROSC (que disciplina as parcerias entre administração pública e OSC, incluindo, de forma expressa, outra modalidade de acordo de cooperação). A primeira forma costuma ser utilizada, inclusive - mas não apenas -, quando o particular não se enquadra sob a definição legal de OSC. Pode ocorrer, por exemplo, quando figura, na condição de parceiro privado, uma sociedade empresarial. E, considerando a ausência de recursos públicos, seriam aplicáveis a essa relação as condições do art. $116, \S 1^{\circ}$, da lei de licitações e contratos administrativos, que correspondem apenas aos incisos I, II, III e VI. Nesse sentido, cabe destacar trecho do entendimento da Advocacia Geral da União sobre o assunto:

Parecer n. ${ }^{\circ}$ 01068/2016/AMA/CGJLC/CONJURᄀMP/CGU/AGU. [...] 7. Como os Acordos de Cooperação Técnica consistem em ajustes firmados por entidades públicas de qualquer espécie ou entre estas e organizações particulares, com o fim de realizar projetos de interesse comum dos partícipes, aplicam, no presente caso, as disposições concernentes à Lei $\mathrm{n}^{\circ}$ 8.666, de 21 de junho de 1993 - exceto as incompatíveis, conforme se denota de seu art. 116: [...] (AGU, 2016)

O entendimento acima é de 2016, quando o MROSC já vigorava. Ou seja, a cooperação técnica amparada pelo art. 116 da lei de licitações e contratos administrativos não deixou de ser viável para disciplinar, inclusive, relações com OSC. Vale lembrar que o MROSC define, essencialmente, um regime jurídico de fomento público, que se materializa pela destinação de recursos públicos para projetos e atividades de OSC. Assim, iniciativas que envolvem, ao contrário, a destinação de recursos privados para finalidades de interesse público, a rigor, não se amoldariam perfeitamente ao MROSC. Ou seja, sob uma visão sistêmica, é justificável sustentar que algumas cooperações, como as de ISP, não deveriam ser enquadradas sob o regime jurídico do MROSC, mas seguir sob as normas do art. 116 da lei de licitações e contratos administrativos.

Porém, como foi apontado, é muito provável que o acordo de cooperação para ações de ISP executadas por OSC seja celebrado sob as normas do MROSC, por força do art. 41 da lei, já citado. Assumindo essa hipótese, é preciso compreender quais são as suas consequências para o tema aqui estudado ${ }^{4}$.

\subsection{Acordo de cooperação no MROSC}

O MROSC, lei de caráter nacional, entrou em vigor em janeiro de 2016, para o governo federal, estados e Distrito Federal e, em janeiro de 2017, para municípios. O novo diploma legal institui:

[...] normas gerais para as parcerias entre a administração pública e organizações da sociedade civil, em regime de mútua cooperação, para a consecução de finalidades de interesse público e recíproco, mediante a execução de atividades ou de projetos previamente estabelecidos em planos de trabalho inseridos em termos de colaboração, em termos de fomento ou em acordos de cooperação (BRASIL, 2014, grifo do autor).

Ocorre que o tratamento conferido pela lei ao acordo de cooperação não foi abrangente e minucioso como o que se deu às modalidades de contratação denominadas termo de colaboração e termo de

4. Esta regra, no entanto, deveria ser interpretada com cuidado, pois não é apenas a condição subjetiva do parceiro privado - OSC - que deve justificar a aplicação da lei, mas também a pertinência das diretrizes, fundamentos e finalidades da lei do MROSC para a relação jurídica que venha a ser estabelecida. 
fomento. Para esses, o MROSC concebe um regime jurídico com foco nas parcerias que envolvem repasses de recursos financeiros às OSC. Ao acordo de cooperação, por não envolver transferências financeiras de origem pública, foi dado um tratamento minimalista. Tanto é assim que a exigência de um agente público responsável pela gestão de parceria fica restrita às parcerias com movimentação de recursos públicos. Além disso, os requisitos institucionais a serem demonstrados pela OSC para a celebração desse instrumento são substancialmente reduzidos pela lei. E, ainda, o instrumento do acordo comporta apenas as cláusulas e condições compatíveis com a ausência de repasses públicos ${ }^{5}$.

A lei prevê, ainda, dois processos distintos de formação para os acordos de cooperação, nos termos de seu art. 29: o do instrumento que se faz acompanhar de compartilhamento patrimonial da administração pública em favor da OSC e o daquele que não o faz . No primeiro tipo é exigível, em regra, o chamamento público, mesmo que a OSC venha a garantir recursos para despesas, uma vez que a administração pública concorre com a viabilização do objeto, provendo o suporte físico necessário. O segundo tipo é aplicável para projetos ou atividades que não envolvam a transferência de bens por parte do parceiro público. A tipologia das estratégias de "aproximação com políticas públicas” identificadas pelo Censo GIFE 2018 trata, em grande medida, de situações enquadráveis no segundo tipo de instrumento.

No entanto as delimitações aqui apontadas, que distinguem duas espécies de acordo de cooperação, podem não ser devidamente reconhecidas na prática. Pior: é possível que pouca distinção se faça mesmo face aos instrumentos que envolvem transferências financeiras - termos de fomento e de colaboração. $\mathrm{O}$ que significa, em poucas palavras, que, ao particular, tendencialmente, podem ser impostas condições mais rígidas do que o necessário, ou até desproporcionais.

\subsection{Acordos de cooperação e os riscos da (in)distinção entre as diversas modalidades de parceria no MROSC}

Embora a disciplina do acordo de cooperação, no MROSC, excepcione diversas exigências - aplicáveis apenas às modalidades que envolvem transferências financeiras -, é certo que o texto legal não foi suficientemente claro. Assim, dependeria do tratamento regulamentar a definição de condições mais exatas, especialmente para delimitar o maior grau de horizontalidade dessa relação jurídica diante da ausência de bens ou recursos públicos na relação jurídica. Cada ente da federação dispõe de competência para editar a regulamentação e, porém, até agora, os decretos não refletem essa delimitação.

Mesmo no caso de uma regulamentação detalhada, como é o caso do decreto federal 8.726/16 (BRASIL, 2016, artigos $5^{\circ}$ e $6^{\circ}$ ), não se pode reconhecer, nele, uma disciplina marcada pela precisão. $O$ decreto é aplicável aos acordos, "no que couber", e assume variáveis como a "complexidade" do objeto a ser pactuado para estabelecer maior ou menor rigor das normas incidentes. Ou seja, confere alto (e indesejável) nível de discricionariedade para o administrador público definir as condições aplicáveis aos acordos. Ao mesmo tempo, ainda que se admita a simplificação ou a dispensa de prestação de contas, que são previstas no caso de um acordo de cooperação sem compartilhamento de bens públicos, essa possibilidade é apenas facultada, em uma disposição demasiadamente vaga ( $\operatorname{art.} 6^{\circ}$, § $2^{\circ}$, II).

5 Lei 13.019/14. “Art. $2^{\circ}$. [...] VI - gestor: agente público responsável pela gestão de parceria celebrada por meio de termo de colaboração ou termo de fomento, designado por ato publicado em meio oficial de comunicação, com poderes de controle e fiscalização; [...] Art. 33 [...] $\S 1^{\circ} \mathrm{Na}$ celebração de acordos de cooperação, somente será exigido o requisito previsto no inciso I. [...] Art. 42. As parcerias serão formalizadas mediante a celebração de termo de colaboração, de termo de fomento ou de acordo de cooperação, conforme o caso, que terá como cláusulas essenciais: [...] III - quando for o caso, o valor total e o cronograma de desembolso; [...]; X - a definição, se for o caso, da titularidade dos bens e direitos remanescentes na data da conclusão ou extinção da parceria e que, em razão de sua execução, tenham sido adquiridos, produzidos ou transformados com recursos repassados pela administração pública; [...] XV - o livre acesso dos agentes da administração pública, do controle interno e do Tribunal de Contas correspondente aos processos, aos documentos e às informações relacionadas a termos de colaboração ou a termos de fomento, bem como aos locais de execução do respectivo objeto; [...]" (BRASIL, 2014, grifos do autor).

6 Lei 13.019/14. "Art. 29. Os termos de colaboração ou de fomento que envolvam recursos decorrentes de emendas parlamentares às leis orçamentárias anuais e os acordos de cooperação serão celebrados sem chamamento público, exceto, em relação aos acordos de cooperação, quando o objeto envolver a celebração de comodato, doação de bens ou outra forma de compartilhamento de recurso patrimonial, hipótese em que o respectivo chamamento público observará o disposto nesta Lei” (BRASIL, 2014, grifos do autor). 
O exagero é flagrante. Isso porque não haveria razão para cogitar sobre "prestação de contas" daquele que financiou inteiramente as atividades ou o projeto e não recebeu qualquer bem ou recurso público. O dever de prestar contas só pode ser interpretado à luz do art. 70, Parágrafo Único, da Constituição Brasileira, que determina:

Art. 70 [...] Parágrafo único. Prestará contas qualquer pessoa física ou jurídica, pública ou privada, que utilize, arrecade, guarde, gerencie ou administre dinheiros, bens e valores públicos ou pelos quais a União responda, ou que, em nome desta, assuma obrigações de natureza pecuniária (BRASIL, 1988, grifo do autor).

Mesmo em se tratando de uma prestação de contas voltada à mensuração dos resultados, como determina o MROSC, a exigência seria desproporcional nas hipóteses em que o particular não recebeu e nem mobilizou dinheiro ou bens públicos para atingir os resultados pactuados, aportando recursos próprios ou de terceiros (particulares), tão somente. E note-se: à exigência de prestação de contas se soma, ainda, a sujeição do particular ao rigoroso processo sancionatório previsto na lei, com penalidades que abrangem a advertência, a suspensão do direito de contratar com entes públicos e a declaração de inidoneidade - concebidas, a toda evidência, para situações de mau uso dos recursos públicos? ${ }^{7}$.

Em poucas palavras, a regulamentação federal poderia ser muito mais enfática, afastando, genericamente, e não de modo casuístico, exigências claramente incompatíveis com a lógica dos acordos de cooperação.

Os excessos de burocracia e a insegurança jurídica, no entanto, podem ser mais acentuados no ambiente subnacional. Analisando os decretos disponibilizados pelo GIFE na plataforma Sustenta OSC, são identificáveis normas ainda mais vagas e imprecisas, sendo possível extrair as categorizações mostradas pelo Quadro 1.

\section{Quadro 1 - Legislação estadual a respeito do MROSC}

\section{Abordagem regulamentar do acordo de cooperação}

Disciplina próxima à indistinção entre as modalidades de parceria com e sem recursos/ bens públicos

Implicitamente, apenas, admite um rito mais simplificado para a cooperação sem compartilhamento patrimonial, mas sem uma disciplina específica e sistemática

Disciplina idêntica à estabelecida pelo decreto federal

Disciplina próxima à estabelecida pelo decreto federal

Não disciplina o acordo de cooperação

Fonte: Elaboração própria a partir do Portal Sustenta OSC, GIFE.
UF

PA, RO, AP, TO, MT, SE, $B A, P I, P R$ e RS

SP

MS e MA

CE, MG, SC e DF

$\mathrm{AL}$

7 Aliás, há de se questionar se a imposição de cláusulas sobre prestações de contas e sanções administrativas seria justificável, como preceitua o decreto federal 8.726/16, até mesmo em acordos de cooperação acompanhados de compartilhamento patrimonial. Isso porque, pelo que determina a lei, a transferência de bens ao particular é materializada por meio de instrumento apropriado (art. 29), o que significa que as obrigações quanto ao regular uso ou destinação do patrimônio público já estariam devidamente endereçadas em contrato específico. É dizer: uma eventual permissão de uso, celebrada em paralelo ao acordo de cooperação, já incluiria todas as obrigações e o rol de sanções aplicáveis para as hipóteses de descumprimento do contrato. 
Quanto aos estados e outras unidades da federação que não regulamentaram o MROSC, é possível que haja aplicação, por analogia, do decreto federal 8.726/16. E há também entes públicos que definem minutas-padrão para todas as formas de parceria, incluindo os acordos de cooperação. Pelo que se observa da prática administrativa, a tendência de padronização dos modelos é muito grande, de tal modo que se insurgir contra condições definidas em um determinado acordo pode ser bastante difícil.

No caso de Alagoas, por exemplo, a Procuradoria Geral do Estado já disponibiliza o modelo de instrumento (ALAGOAS, 2020) com parâmetros muito próximos aos de termos de fomento e colaboração - instrumentos que envolvem repasses públicos. Contrariando regras expressas do MROSC, como os $\operatorname{artigos} 2^{\circ}, \mathrm{VI}$, e 42 , a minuta estabelece cláusulas que, possivelmente, inibiriam parceiros privados a celebrar acordos de cooperação com o estado. Destacam-se alguns trechos:

\section{MINUTA DE ACORDO DE COOPERAÇÃO}

[...]

CLÁUSULA TERCEIRA - DAS OBRIGAÇÕES DA ORGANIZAÇÃO DA SOCIEDADE CIVIL

3.1. São obrigações da organização da sociedade civil:

[...]

3.1.2. Registrar no SICONV os atos de aplicação de recursos próprios, se for o caso, e a prestação de contas do presente Acordo de Cooperação.

$[\ldots]$

3.1.3.4. Situação da prestação de contas da parceria, que deverá informar a data prevista para a sua apresentação, a data em que foi apresentada, o prazo para a sua análise e o resultado conclusivo;

$[\ldots]$

3.1.5. Prestar contas da boa e regular execução do objeto do Acordo de Cooperação, em obediência às metas, fases ou etapas do Plano de Trabalho, no prazo de até noventa dias a partir do término da vigência da parceria ou, no caso de a parceria exceder um ano, no final de cada exercício.

3.1.6. Manter, durante o prazo de 10 (dez) anos, contado do dia útil subsequente ao da prestação de contas, em seu arquivo, os documentos originais que compõem a prestação de contas.

\section{CLÁUSULA NONA - DA PRESTAÇÃO DE CONTAS}

9.1. A prestação de contas e todos os atos que dela decorram dar-se-ão no SICONV, permitindo a visualização por qualquer interessado.

9.1.1. Os documentos incluídos pela entidade no SICONV, desde que possuam garantia da origem e de seu signatário por certificação digital, serão considerados originais para os efeitos de prestação de contas.

9.1.2. As impropriedades que deram causa à rejeição da prestação de contas serão registradas no SICONV.

9.2. A prestação de contas apresentada pela organização da sociedade civil deverá conter elementos que permitam ao gestor da parceria avaliar $\mathrm{o}$ andamento ou concluir que o seu objeto foi executado conforme pactuado, com a descrição pormenorizada das atividades realizadas e a comprovação do alcance das metas e dos resultados esperados, até o período de que trata a prestação de contas, a exemplo, dentre outros, das seguintes informações e documentos: [...].

12. CLÁUSULA DOZE - DAS RESPONSABILIZAÇÕES E DAS SANÇÕES

12.1. Pela execução da parceria em desacordo com o Plano de Trabalho e com as normas da Lei n ${ }^{\circ}$ 13.019, de 31 de julho de 2014, e da legislação específica, a administração pública poderá, garantida a prévia defesa, aplicar à organização da sociedade civil as seguintes sanções: [...] (ALAGOAS, 2020, grifos do autor). 
Suponha-se, assim, uma iniciativa de ISP voltada ao desenvolvimento de ações na área da educação pública e que venha a se sujeitar aos parâmetros da minuta acima. Admitindo que a OSC esteja sediada na cidade de Belo Horizonte e selecione ou desloque uma equipe para realizar o projeto em Maceió ou em cidades do interior de Alagoas. Não seria razoável que, além de mobilizar equipe técnica, a organização tivesse de atender obrigações de índole puramente administrativa, como registrar atos de despesas, realizadas com recursos próprios, na plataforma do Sistema de Convênios (Siconv). Além disso, a exigência de prestação de contas, em um acordo sem qualquer recurso ou bem público, seria claramente inconstitucional. E mais: a sujeição do particular a todo arsenal sancionatório da lei do MROSC, nesse cenário, seria desproporcional e inadequada, sendo suficientes as cláusulas de extinção antecipada do ajuste e a incidência - inafastável - do sistema de tutela da moralidade administrativa, em especial, da lei de improbidade (BRASIL, 1992).

Situam-se, aqui, apenas alguns dos problemas facilmente avistados pelo teor das normas de regulamentação e por um modelo de padronização. O que ocorre, no entanto, é que a confusão interpretativa pode ser muito maior, na prática, uma vez que o MROSC impõe inovações de difícil assimilação, induzindo gestores públicos e, sobretudo, servidores de consultoria jurídica e de controle, a generalizar as regras para todo e qualquer tipo de relação com OSC. Não deverá surpreender, assim, se entes públicos passarem a exigir, por exemplo, chamamento público para qualquer iniciativa de ISP em "aproximação com políticas públicas", ainda que ausentes os requisitos legais, mas apenas por uma predominante cultura de "excesso de controle" (GUIMARÃES, 2016).

\section{CONSIDERAÇÕES FINAIS}

O MROSC não foi concebido propriamente para disciplinar relações típicas de ISP - assumindo, como tais, aquelas que mobilizam apenas recursos privados para uma iniciativa de interesse público. Essa questão leva aos próprios limites do MROSC para disciplinar relações entre entes públicos e OSC. Considerando o pouco tempo de vigência e, mais do que isso, a imprecisão de algumas de suas normas, muitos equívocos e excessos terão de ser superados.

Não se quer dizer, com isso, que o acolhimento do ISP para "aproximações com políticas públicas" deva ser simplificado a qualquer custo. Obviamente, uma proposta de parceria exige avaliação técnica e jurídica para seu acolhimento, com observância de princípios administrativos. A abordagem, no entanto, deve ser mais voltada ao rigor, à aderência e à conveniência da iniciativa frente às diretrizes de cada política pública.

Nesse sentido, é preciso lembrar que o acordo de cooperação moldado sob o art. 116 da lei de licitações e contratos também se mostra adequado para as relações que materializem ISP, pois admite, igualmente, a realização de "projetos de interesse comum dos partícipes", como realçado por parecer da AGU (2016). Há, no entanto, o risco de revogação dessa norma pela proposta de reforma da lei de licitações que se encontra mais avançada no Congresso (CD, 1995). Assim, remanesceria apenas a modalidade de acordo de cooperação prevista na lei do MROSC, com todas as imprecisões que foram debatidas neste texto.

Tais constatações parecem justificar a atenção e a mobilização dos investidores sociais privados para a segurança jurídica do ambiente de atuação das OSC, particularmente quanto aos impactos negativos do MROSC - que, aparentemente, não foram estimados nesse campo. Parece oportuno sensibilizar atores públicos relevantes sobre os limites da nova legislação de parcerias e reclamar por sua correta regulamentação e aplicação. Na prática, significa reconhecer o acordo de cooperação como uma relação jurídica marcada por maior horizontalidade e para a qual muitas exigências do MROSC devem ser afastadas. 


\section{REFERÊNCIAS}

AGU - Advocacia Geral da União. Parecer 01068/2016/AMA/CGJLC/CONJURᄀMP/CGU/AGU. 2016. Disponível em: http://www.consultaesic.cgu.gov.br/busca/dados/Lists/Pedido/Attachments/522010/RESPOSTA RECURSO_1_AnexoIV_03950003100201612.pdf. Acesso em: 15.01.2020.

ALAGOAS. Procuradoria Geral do Estado. Convênios e Parcerias. 2020. Disponível em: <http://www. procuradoria.al.gov.br/servicos/editais-e-contratos/convenios>. Acesso em: 15.01.2020.

BRASIL. Constituição da República Federativa do Brasil. 1988. Brasília, DF. Disponível em: <http:// www.planalto.gov.br/ccivil_03/constituicao/constituicao.htm>. Acesso em: 01.02.2020.

BRASIL. Decreto 8.726, de 27 de abril de 2016. Regulamenta a Lei 13.019, de 31 de julho de 2014, para dispor sobre regras e procedimentos do regime jurídico das parcerias celebradas entre a administração pública federal e as organizações da sociedade civil. Disponível em: < http://www.planalto.gov.br/ ccivil_03/_ato2015-2018/2016/decreto/d8726.htm>. Acesso em: 10.02.2020.

BRASIL. Decreto 9.764, de 11 de abril de 2019. Dispõe sobre o recebimento de doações de bens móveis e de serviços de pessoas físicas ou jurídicas de direito privado pelos órgãos e pelas entidades da administração pública federal direta, autárquica e fundacional. Disponível em: <http://www.planalto. gov.br/ccivil_03/_ato2015-2018/2016/decreto/d8726.htm>. Acesso em: 03.02.2020.

BRASIL. Lei 13.019 de 31 de julho de 2014. Estabelece o regime jurídico das parcerias entre a administração pública e as organizações da sociedade civil. Disponível em: <http://www.planalto.gov. br/ccivil_03/_ato2011-2014/2014/lei/113019.htm>. Acesso em: 01.02.2020.

BRASIL. Lei 13.800, de 4 de janeiro de 2019. Autoriza a administração pública a firmar instrumentos de parceria e termos de execução de programas, projetos e demais finalidades de interesse público com organizações gestoras de fundos patrimoniais; altera as Leis 9.249 e 9.250, de 26 de dezembro de 1995, 9.532, de 10 de dezembro de 1997, e 12.114 de 9 de dezembro de 2009; e dá outras providências. Disponível em: <http://www.planalto.gov.br/ccivil_03/_Ato2019-2022/2019/Lei/L13800.htm> Acesso em: 10.02.2020.

BRASIL. Lei 8.666, de 21 de junho de 1993. Regulamenta o art. 37, inciso XXI, da Constituição Federal, institui normas para licitações e contratos da Administração Pública e dá outras providências. Disponível em: 〈http://www.planalto.gov.br/ccivil_03/leis/18666cons.htm>. Acesso em: 01.02.2020.

BRASIL. Lei 8.429, de 2 de junho de 1992. Dispõe sobre as sanções aplicáveis aos agentes públicos nos casos de enriquecimento ilícito no exercício de mandato, cargo, emprego ou função na administração pública direta, indireta ou fundacional e dá outras providências. Disponível em: <http://www.planalto. gov.br/ccivil_03/leis/18429.htm>. Acesso em: 01.03.2020.

BRASIL. Lei 10.406 de 10 de janeiro de 2002. Institui o Código Civil. Disponível em: <http://www. planalto.gov.br/ccivil_03/leis/2002/110406.htm>. Acesso em: 01.02.2020.

CD - CÂMARA DOS DEPUTADOS. Projeto de Lei 1292/95. Estabelece normas gerais de licitação e contratação para as administrações públicas diretas, autárquicas e fundacionais da União, dos Estados, do Distrito Federal e dos Municípios; altera as Leis 13.105, de 16 de março de 2015 (Código de Processo Civil), 8.987, de 13 de fevereiro de 1995, e 11.079, de 30 de dezembro de 2004, e o Decreto-Lei 2.848, de 7 de dezembro de 1940 (Código Penal); e revoga dispositivos da Lei 12.462, de 4 de agosto de 2011, e as Leis 8.666, de 21 de junho de 1993, e 10.520, de 17 de julho de 2002. Disponível em: <https://www. camara.leg.br/proposicoesWeb/fichadetramitacao?idProposicao=16526>. Acesso em: 01.02.2020. 
CARVALHAES NETO, Eduardo Hayden. Contratos privados da administração pública: uma análise do regime jurídico aplicável. Tese de Doutorado. São Paulo: Faculdade de Direito da Universidade de São Paulo, 2011.

DI PIETRO, Maria Sylvia Zanella. Direito administrativo. São Paulo: Atlas, 2010, $23^{\text {a }}$ edição.

GIFE - Grupo de Institutos, Fundações e Empresas. Censo GIFE 2018. 2019. Disponível em: https:// sinapse.gife.org.br/download/censo-gife-2018. Acesso em: 22/01/2020.

GIFE - Grupo de Institutos Fundações e Empresas. Investimento social privado. s.d. Disponível em: https://gife.org.br/investimento-social-privado/. Acesso em: 15/01/2020.

GUIMARÃES, Fernando V. O direito administrativo do medo: a crise da ineficiência pelo controle. Revista Direito do Estado, 2016, n. 71. Disponível em: http://www.direitodoestado.com.br/colunistas/ fernando-vernalha-guimaraes/o-direito-administrativo-do-medo-a-crise-da-ineficiencia-pelo-controle.

HIRATA, Augusto J. Fundos patrimoniais e organizações da sociedade civil. São Paulo: GIFE/FGV Direito, 2019. 
O AUTOR

\section{Thiago Lopes Ferraz Donnini \\ thiagodonnini@gmail.com}

Bacharel em Direito pela Universidade Mackenzie. Especialista em Direito Constitucional e Mestre em Direito do Estado pela Pontifícia Universidade Católica (PUC/SP). Foi professor de direito administrativo e de direito constitucional em diversas instituições. Foi pesquisador junto à Coordenadoria de Pesquisa Jurídica Aplicada da FGV Direito SP. É autor de "Parcerias sociais: o novo marco regulatório das organizações da sociedade civil” (Juruá, 2019). É advogado em direito administrativo. 


\title{
artigos GIFE
}

Supervisão: José Marcelo Zacchi e Gustavo Bernardino

Coordenação: Carolina Magosso

Produção editorial: Gleice Regina Guerra

Apoio: Graziela Santiago

Comitê de seleção: Ana Lúcia D'Império Lima, Fábio Silva

Tsunoda, Laura Leal e Lívia Menezes Pagotto

Diagramação: Alastra, Comunica!

Impressão: Forma Certa

ISSN: 2674-8061

DOI: doi.org/10.33816/gife.20200202a2

(C) 2019 GIFE - Grupo de Institutos Fundações e Empresas

\section{(C) (i) ()}

Este material é disponibilizado sob a licenca Creative Commons Atribuição Não Comercial 4.0 Internacional. http://creativecommons.org/licenses/by-nc/4.0

As opiniões e análises expressas nesta publicação não necessariamente refletem as do GIFE.

\author{
Apoio institucional \\ Alana \\ Ford Foundation \\ Fundação Bradesco \\ Fundação Lemann \\ Fundação Tide Setubal \\ Instituto Unibanco \\ Laudes Foundation
}

